Fourth International Conference on Sustainable Construction Materials and Technologies http://www.claisse.info/Proceedings.htm

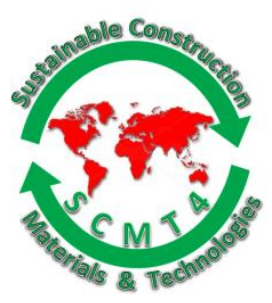

SCMT4

Las Vegas, USA, August 7-11, 2016

\title{
Aluminum Dust Recycled as Aerating Agent for the Production of Autoclaved Aerated Concrete
}

\author{
Yiquan Liu', Bo Siang Leong ${ }^{2 a}$, and En-Hua Yang ${ }^{2 b}$ \\ ${ }^{1}$ Energy Research Institute @NTU (ERI@N), Interdisciplinary Graduate School, Nanyang Technological \\ University - 1 CleanTech Loop, \#06-04 CleanTech One, Singapore 637141. \\ Email: <liuy0102@e.ntu.edu.sg>. \\ ${ }^{2}$ School of Civil and Environmental Engineering, Nanyang Technological University - N1-01a-29, 50 \\ Nanyang Avenue, Singapore 639798, \\ ${ }^{2 a}$ Email: 〈bsleong1@e.ntu.edu.sg>, ${ }^{2 b}$ Email:<ehyang@ntu.edu.sg>.
}

\begin{abstract}
Aluminum dust is a by-product of aluminum dross recycling industry. There is some metallic aluminum in aluminum dust from composition analysis. In this paper, aluminum dust is used as aerating agent to replace metallic aluminum powder for the production of autoclaved aerated concrete (AAC). The results showed that aluminum dust can successfully replace aluminum powder in AAC production and the gas generation capacity of aluminum dust is around one sixteenth of that of aluminum powder. However, the incorporation of aluminum dust into AAC paste can make a fast yield stress gain to the AAC paste. Therefore, comparing with aluminum powder AAC, aluminum dust AAC has smaller pore size, lower porosity, higher density and higher compressive strength. Furthermore, the porosity of aluminum dust AAC cannot be further increased by increasing aluminum dust dosage because higher aluminum dust dosage leads to a faster yield stress gain. In general, this paper revealed a viable way to recycle aluminum dust in AAC production rather than direct landfill, but further study to optimize the property of aluminum dust AAC needs to be done in future.
\end{abstract}

\section{INTRODUCTION}

Aluminum dross is the by-product generated from the aluminum smelting industry. Aluminum dross can be mechanically recycled to separate the residual aluminum metal from the aluminum oxide. The recycled metallic aluminum is cast into ingot for resale. Figure 1 shows the flow chart of aluminum dross recycling process. As can be seen, another by-product, aluminum dust, is generated from the aluminum dross recycling process. 


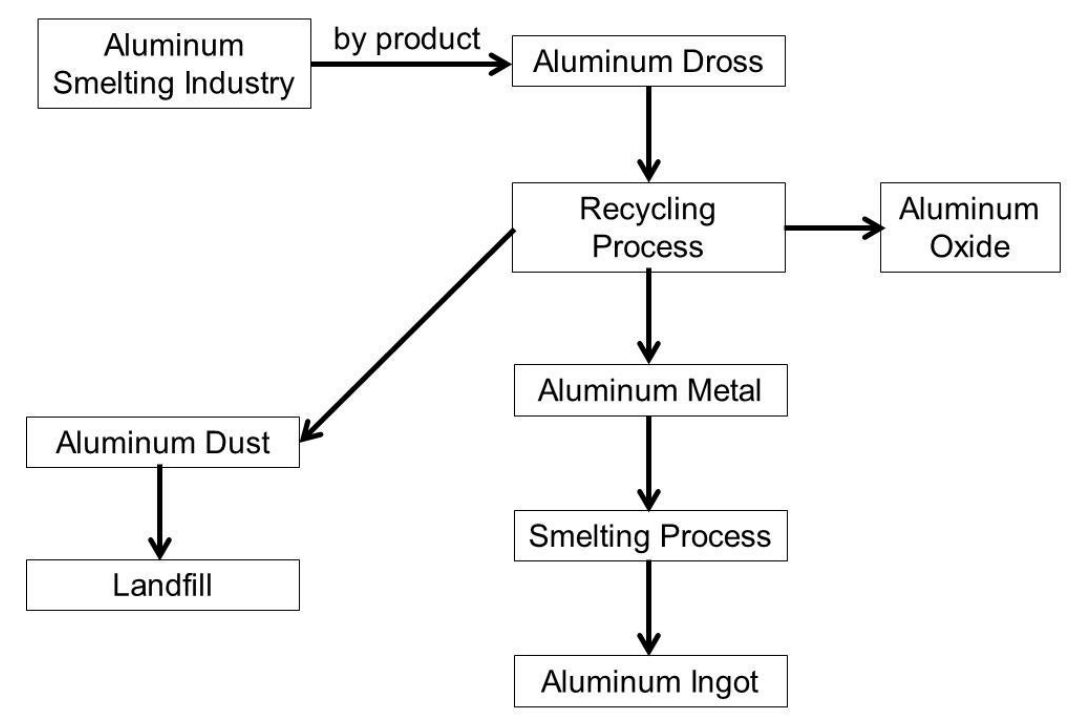

Figure1. Flow Chart of Aluminum Dross Recycling Process

As aluminum dust has low metallic aluminum content, it is not economically attractive to further extract aluminum metal from the dust. Therefore, aluminum dust is often considered as waste and disposed of by landfill. Aluminum dust may cause serious explosion [Eckhoff 2003; Myers and Timothy 2008; Ebadat et al 2007] and is regarded as hazardous waste. The cost of hazardous waste landfill is several times higher than that of non-hazardous waste landfill [Stephen 2003], which can greatly offset the profit made from aluminum dross recycling. It is of great interest to utilize aluminum dust and deviate it from landfill.

Aerated concrete is a lightweight material in which a uniform cellular structure of air voids distributed throughout a matrix of cement paste of mortar. With extremely low density $(500 \mathrm{~kg} / \mathrm{m} 3)$ and thermal conductivity $(0.1 \mathrm{~W} / \mathrm{m}-\mathrm{K})$, aerated concrete is an idea material for thermal insulation and sound-proofing. Aerated concrete can be used for floors, trench fills, roof insulation and other insulating purposes, as well as to make masonry units. The introduction of gas in aerated concrete is achieved usually by the inclusion of finely divided aluminum powder. The aluminum reacts with the soluble alkalis in the cement slurry to generate small bubbles of hydrogen. Typical mix proportion and cost structure of autoclaved aerated concrete can be found in paper [Song et al 2015], and it can be found that aluminum powder, while only occupies a small portion/dosage in the mix design, represents about $10 \%$ of the total material cost of aerated concrete. In this paper, aluminum dust is used as gas forming agent to replace costly aluminum powder for the production of aerated concrete.

\section{EXPERIMENTAL PROGRAM}

Materials. Aluminum dust was collected from a factory which recycles aluminum dross to produce aluminum ingot. Figure 2 shows the XRD pattern of aluminum dust. It was found the main crystals in aluminum dust are metallic aluminum and aluminum oxide. Further XRD quantitative analysis shows the mass ratio of metallic aluminum to aluminum oxide is 1 to 3 . The existence of metallic aluminum provides the basis to utilize aluminum dust as aerating agent in aerated concrete production.

To prepare AAC samples, Type I Portland cement, silicon sand, lime, and gypsum are used in this study. Commercial aluminum powder with $99.9 \%$ in purity and an average particle size of $45 \square \mathrm{m}$ is used as 
aerating agent for traditional AAC (control sample) preparation. Tap water was used throughout AAC preparation.

To study the $\mathrm{H} 2$ gas generation property from $\mathrm{Al}$ dust, saturated calcium hydroxide solution was prepared from calcium hydroxide powder and distilled water.

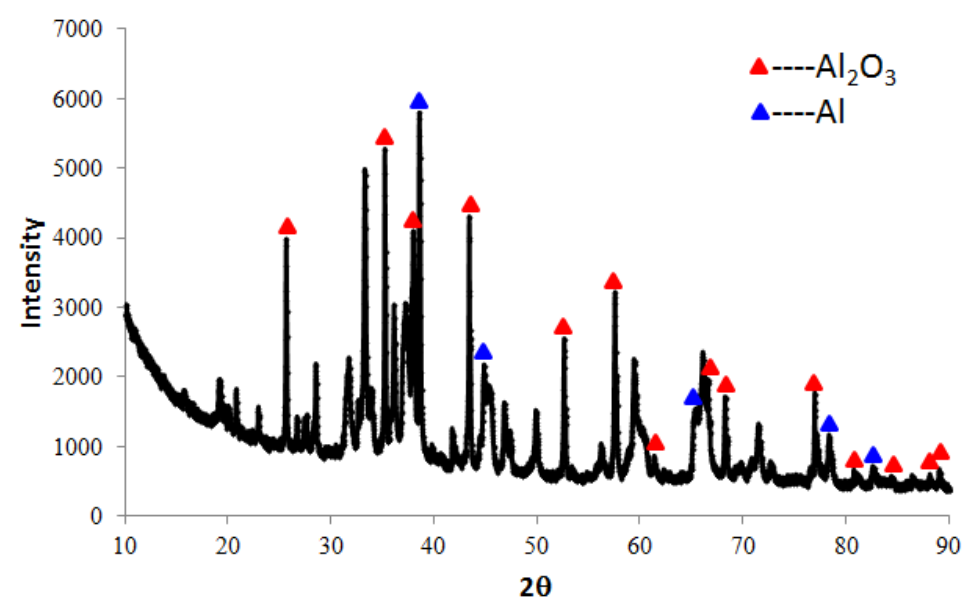

Figure 2. XRD Pattern of Aluminum Dust

Hydrogen gas generation from aluminum dust. A gas over liquid system was developed to study $\mathrm{H} 2$ gas generation from $\mathrm{Al}$ dust. In this system, $1 \mathrm{~g} \mathrm{Al}$ dust powder reacted with $100 \mathrm{ml}$ saturated calcium hydroxide solution under $60 \mathrm{oC}$ and $\mathrm{H} 2$ gas could be generated based on the following equation:

$2 \mathrm{Al}+2 \mathrm{OH}-+6 \mathrm{H} 2 \mathrm{O} \rightarrow 2 \mathrm{Al}(\mathrm{OH}) 4-+3 \mathrm{H} 2$

The generated $\mathrm{H}_{2}$ gas displaced the liquid in gas collection container. By measuring the volume of displaced liquid, the volume of generated $\mathrm{H}_{2}$ gas can be known. The volume of $\mathrm{H}_{2}$ gas generation from 1 $\mathrm{g}$ aluminum powder is also produced in this way for comparison. The reaction would finish when no more $\mathrm{H}_{2}$ gas was generated, and the volume of total $\mathrm{H}_{2}$ is $\mathrm{V}_{\text {total }}$, so the reaction extent can be calculated from the following equation:

Reaction extent $=\left(\mathrm{V}_{\mathrm{t}} / \mathrm{V}_{\text {total }}\right) \times 100 \%$

Where $\mathrm{V}_{\mathrm{t}}$ is the volume of $\mathrm{H}_{2}$ gas generated at time $\mathrm{t}$.

AAC preparation. To study $\mathrm{Al}$ dust as aerating agent, total six mixes were prepared. Table 1 summarizes the mix proportions of six mixes. As can be seen, there are three mixes for Al powder AAC and $\mathrm{Al}$ dust $\mathrm{AAC}$ respectively. For $\mathrm{Al}$ powder $\mathrm{AAC}, \mathrm{Al}$ powder dosage has three levels, i.e. $0.3 \mathrm{~g}, 0.5 \mathrm{~g}$ and $0.7 \mathrm{~g}$. To achieve the same amount of metallic aluminum for aluminum dust AAC, the amount of Al dust used is 15.6 times that of the mass of $\mathrm{Al}$ powder in the corresponding level of $\mathrm{Al}$ powder AAC. This was determined by $\mathrm{H} 2$ gas generation experiments as discussed in RESULTS part which shows Al dust contains 1/15.6 metallic aluminum. To maintain the same water to solid ratio for all the pastes, the amount of silicon sand used for $\mathrm{Al}$ dust $\mathrm{AAC}$ was reduced accordingly based on the amount of $\mathrm{Al}$ dust added. 
Table 1. Mixture Composition (By Mass) of Al powder AACs and Al dust AACs

\begin{tabular}{|c|c|c|c|c|c|c|c|}
\hline Mix & $\begin{array}{c}\text { Silica } \\
(\mathrm{g})\end{array}$ & $\begin{array}{c}\text { Gypsum } \\
(\mathrm{g})\end{array}$ & $\begin{array}{c}\text { Cement } \\
(\mathrm{g})\end{array}$ & $\begin{array}{c}\text { Lime } \\
(\mathrm{g})\end{array}$ & $\begin{array}{c}\text { Al powder } \\
(\mathrm{g})\end{array}$ & $\begin{array}{c}\text { Al dust } \\
(\mathrm{g})\end{array}$ & $\begin{array}{c}\text { Water } \\
(\mathrm{g})\end{array}$ \\
\hline Al powder-AAC-1 & 64 & 3 & 16 & 17 & 0.3 & 0 & 60 \\
\hline Al dust-AAC-1 & 59.32 & 3 & 16 & 17 & 0 & 4.68 & 60 \\
\hline Al powder-AAC-2 & 64 & 3 & 16 & 17 & 0.5 & 0 & 60 \\
\hline Al dust-AAC-2 & 56.2 & 3 & 16 & 17 & 0 & 7.8 & 60 \\
\hline Al powder-AAC-3 & 64 & 3 & 16 & 17 & 0.7 & 0 & 60 \\
\hline Al dust-AAC-3 & 53.08 & 3 & 16 & 17 & 0 & 10.92 & 60 \\
\hline
\end{tabular}

To prepare AAC specimens, the mixing procedures followed: a) Dry mixed silica sand and gypsum; b) Added two-thirds of the total amount of water and mixed for 1 minute; c) Added Portland cement and continued to mix for 1 minute; d) Added lime and one-third of the total amount of water, and then mixed for 1 minute; e) Added the gas generating agent (Al powder or dust) and mixed under high-speed for $15 \mathrm{~s}$. Immediately after mixing, the paste was poured into $5 \mathrm{~cm} \times 5 \mathrm{~cm}$ x $5 \mathrm{~cm}$ cubic mould. The moulds were then kept in environmental chamber and pre-cured under $60^{\circ} \mathrm{C}$ and $98 \mathrm{rh} \%$ for 6 hours. After pre-curing, the specimens were de-moulded and autoclaved in a high pressure autoclave under $210 \mathrm{oC}$ and $2 \mathrm{MPa}$ for 18 hours. Afterwards, the specimens were taken out from autoclave and cut into cubes by saw-cutting and the excessive material at the casting surface due to aerating and rising of the fresh mixture was removed to ensure a flat surface.

Testing. Density was calculated by measuring the dry weight and volume of each specimen. To determine its dry weight, the specimen was oven-dried at $105 \pm 2{ }^{\circ} \mathrm{C}$ for $8 \mathrm{~h}$. Compression test was conducted using the $50 \mathrm{~mm}$ cube. The loading rate was $50 \mathrm{KN} / \mathrm{min}$ and only peak load was recorded. Three samples were tested for both density and compressive strength test and the average value as well as the stand deviation were reported for each test. The specimens are also cut to get the cross section, which could be observed under a Nikon light microscope. The void ratio (porosity) of each sample can be obtained by image analysis from Nikon software.

To interpret the effect of aluminum dust addition on AAC, propertes of AAC paste in fresh state need to be tested. The fresh state means AAC pre-curing stage, i.e. the period when AAC paste was kept in environmental chamber under $60 \mathrm{oC}$ and $98 \mathrm{rh} \%$. The fresh property tests include yield stress and rising height test. For yield stress test, a mini conical mould was used. The specifications of the conical mould were according to ASTM C230/C230M standard. The test procedures were referred to the research paper [Melo et al 2014]. Yield stress was calculated with the following equation:

Yield stress $=($ mass of paste $) /(2 * \pi *$ square of average radius $)$

To measure the rising height of AAC paste, once the mixing procedure finished, $40 \mathrm{ml}$ of AAC paste was poured into a $100 \mathrm{ml}$ measuring cylinder and then the measuring cylinder was kept in environmental chamber under $60 \mathrm{oC}$ and $98 \mathrm{rh} \%$. The height of the paste was recorded from the calibration of measuring cylinder every 5 minutes until no further height increase at all. 


\section{RESULTS}

Hydrogen gas generation from Al dust. Figure 3 shows $\mathrm{H}_{2}$ gas generation from $\mathrm{Al}$ powder and $\mathrm{Al}$ dust with saturated calcium hydroxide solution under $60^{\circ} \mathrm{C}$ as a function of reaction time. As can be seen, $583 \mathrm{ml} \mathrm{H}_{2}$ gas can be generated per gram of $\mathrm{Al}$ powder, while only $37.2 \mathrm{ml} \mathrm{H}_{2}$ gas was generated per gram of $\mathrm{Al}$ dust. Therefore, in term of the $\mathrm{H}_{2}$ gas generation capacity, $1 \mathrm{~g}$ Al powder equals $15.6 \mathrm{~g} \mathrm{Al}$ dust. From the reaction extent curve in Figure 3, Al dust has similar reaction extent development curve with $\mathrm{Al}$ powder during the reaction period, which means regarding $\mathrm{H}_{2}$ gas generation properties, $15.6 \mathrm{~g}$ $\mathrm{Al}$ dust has no difference with $1 \mathrm{~g} \mathrm{Al}$ powder. This provides the basis that the amount of Al dust used in $\mathrm{Al}$ dust $\mathrm{AAC}$ is 15.6 times amount of $\mathrm{Al}$ powder used in $\mathrm{Al}$ powder $\mathrm{AAC}$.
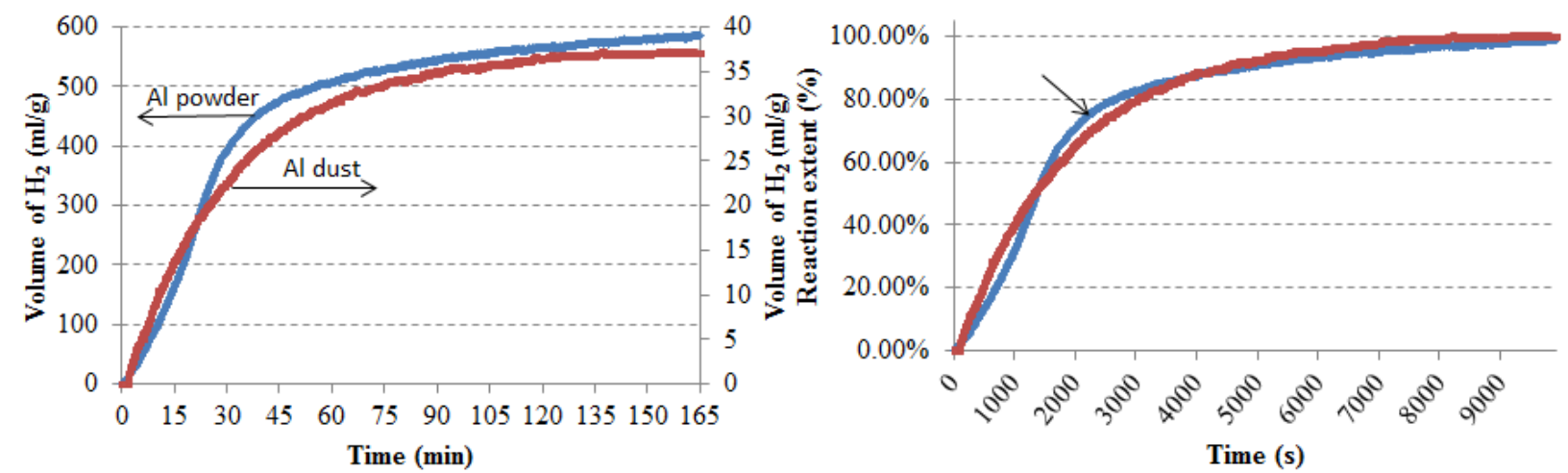

Figure 3. Volume of $\mathrm{H}_{2}$ gas generation (left) and reaction extent (right) from $\mathrm{Al}$ powder and $\mathrm{Al}$ dust as a function of reaction time

Density and void ratio. Figure 4 shows dry density and void ratio of $\mathrm{Al}$ powder $\mathrm{AAC}$ and $\mathrm{Al}$ dust AAC of three metallic aluminum dosage levels. As can be seen, at the same metallic Al dosage level, Al dust AAC has higher dry density and lower void ratio than Al powder AAC. With metallic Al dosage increased from $0.3 \%$ to $0.7 \%$, the density of $\mathrm{Al}$ powder AAC decreased and its void ratio increased. However, Al dust AAC shows completely different performance. Its dry density has no much difference and the void ratio keeps almost the same within the three metallic aluminum dosage levels. Figure 5 shows that dry density and void ratio have linear correlation, which means void ratio is the key factor to determine density for both $\mathrm{Al}$ powder $\mathrm{AAC}$ and $\mathrm{Al}$ dust AAC.
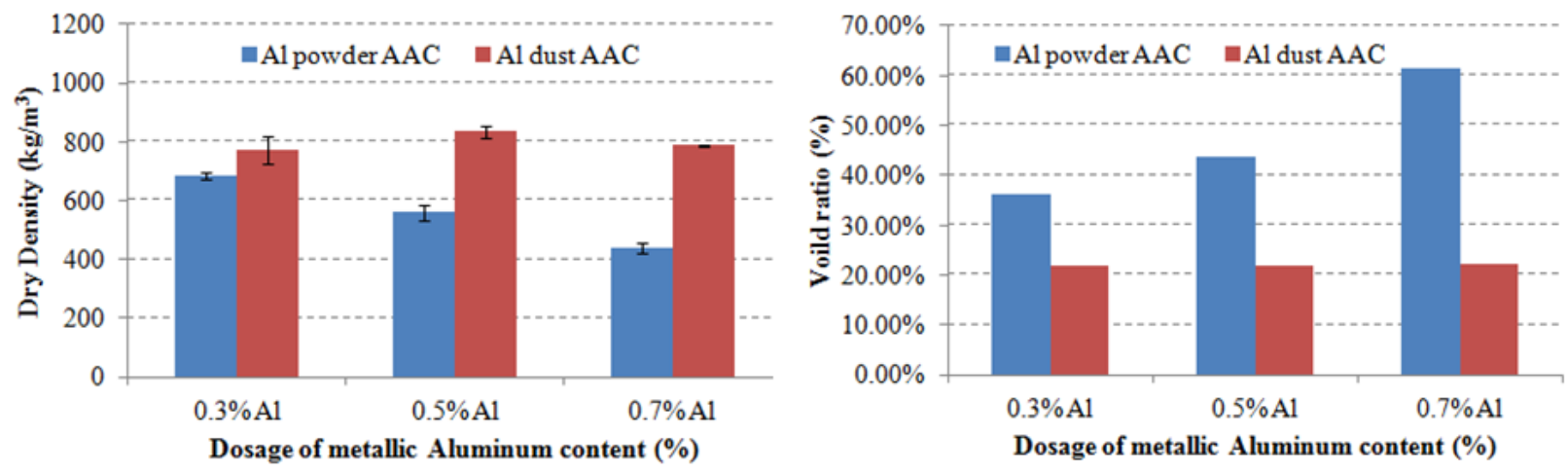

Figure 4. Dry density (left) and void ratio (right) of Al powder AAC and Al dust AAC of three metallic aluminum dosage levels $(0.3 \%, 0.5 \%$ and $0.7 \%)$ 


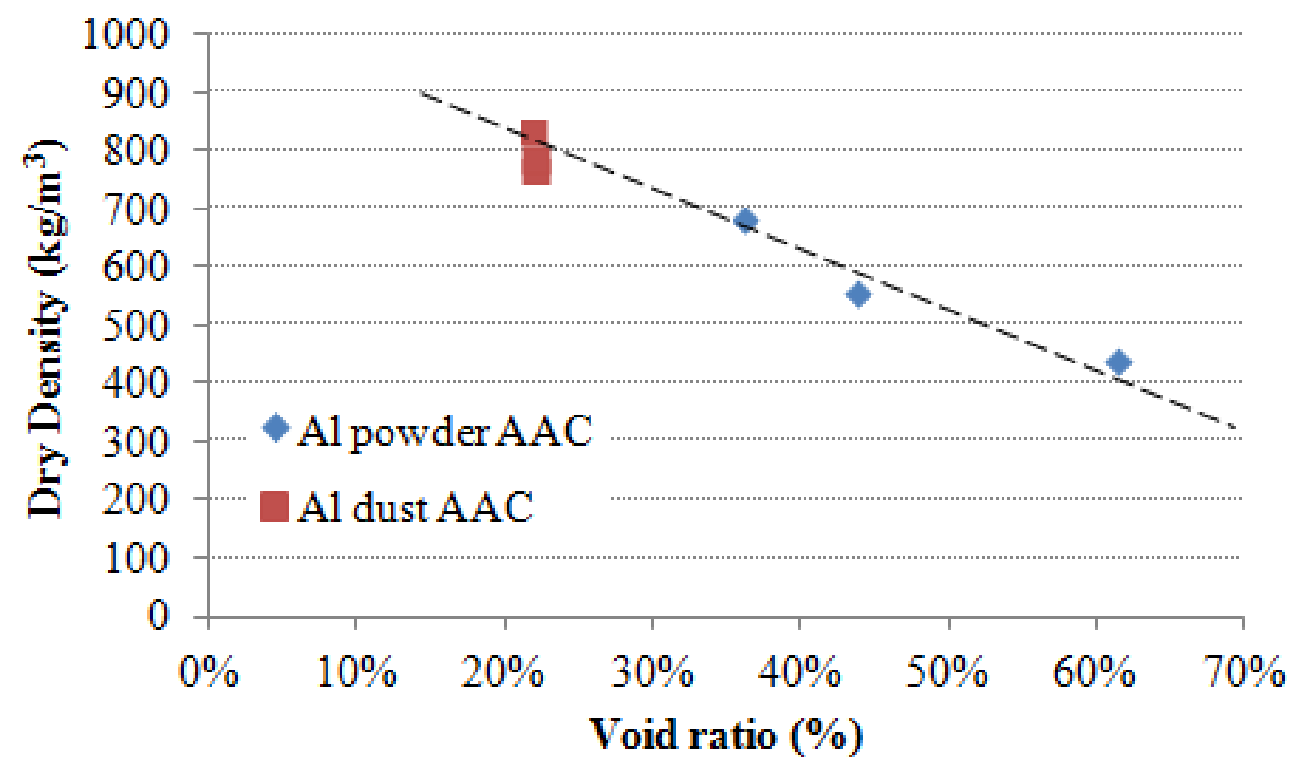

Figure 5. Correlation between dry density and void ratio

Compressive strength. Figure 6 shows the compressive strength of $\mathrm{Al}$ powder AAC and Al dust AAC of three metallic aluminum dosage levels. As can be seen, Al dust AAC has higher compressive strength than Al powder AAC. Further correlation analysis between compressive strength and void ratio / dry density as shown in Figure 7 implies compressive strength has high correlation with void ratio / dry density. The higher compressive strength of $\mathrm{Al}$ dust AAC is due to its lower void ratio and higher dry density.

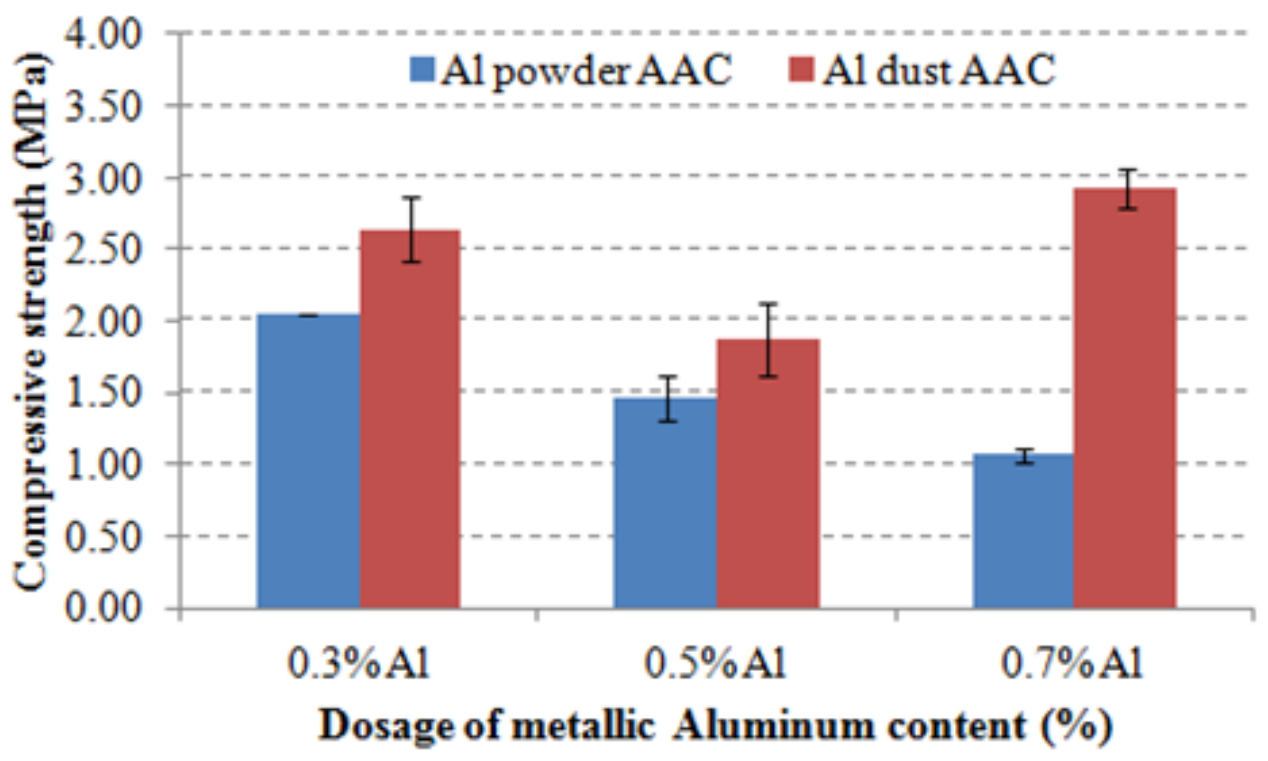

Figure 6. Compressive strength of $\mathrm{Al}$ powder $\mathrm{AAC}$ and $\mathrm{Al}$ dust $\mathrm{AAC}$ under three $\mathrm{Al}$ dosages 

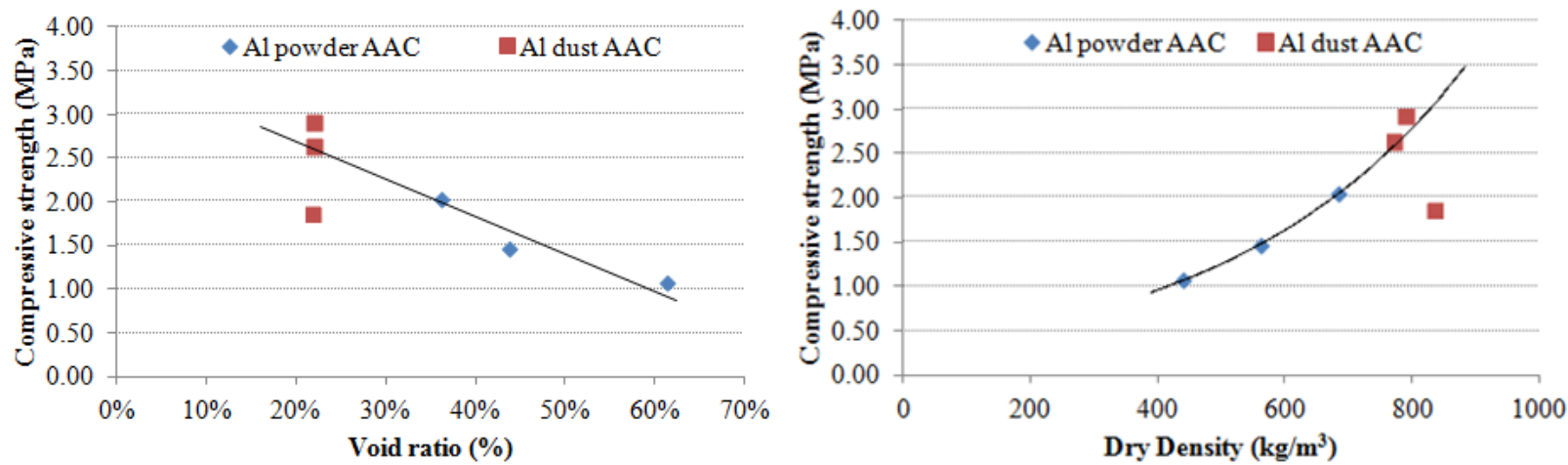

Figure 7. Correlation between compressive strength and void ratio (left) / dry density (right)

\section{DISCUSSIONS}

Based on the above results, no matter what kind of aerating agent used in AAC, void ratio is always the key factor to determine AAC density and compressive strength. In term of $\mathrm{Al}$ dust AAC, there are two questions which need to be clarified:

1. Why $\mathrm{Al}$ dust $\mathrm{AAC}$ has lower void ratio than $\mathrm{Al}$ powder $\mathrm{AAC}$ considering they contain the same amount of metallic aluminum?

2. Why is the void ratio of $\mathrm{Al}$ dust $\mathrm{AAC}$ not able to be increased by increasing $\mathrm{Al}$ dust content?

To answer the two questions, the effects of $\mathrm{Al}$ dust addition on the fresh properties of AAC paste need to be evaluated. Figure 8 shows the correlation between void ratio and rising height. As can be seen, void ratio has high correlation with rising height. The lower void ratio in $\mathrm{Al}$ dust $\mathrm{AAC}$ is due to its lower rising height. From Figure 9, which shows the rising height development with time for Al powder AAC and Al dust AAC with $0.3 \%$ metallic aluminum, Al dust AAC has no further rising after 23 mins, while Al powder AAC continues to rise after 23 mins.

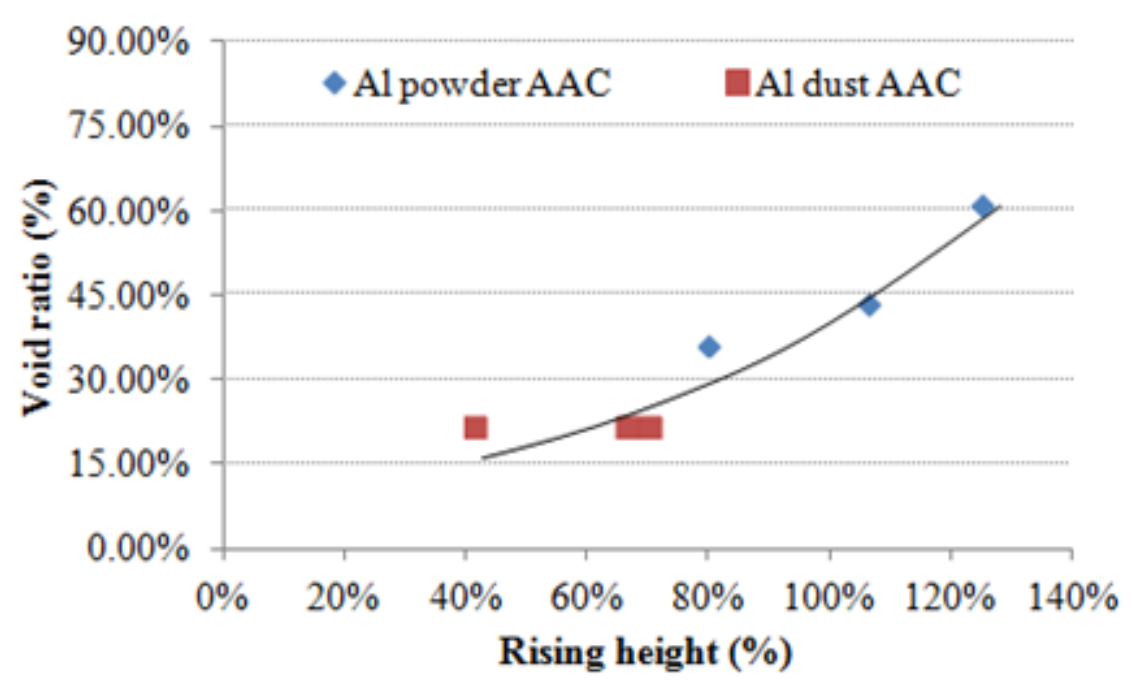

Figure 8. Correlation between void ratio and rising height 


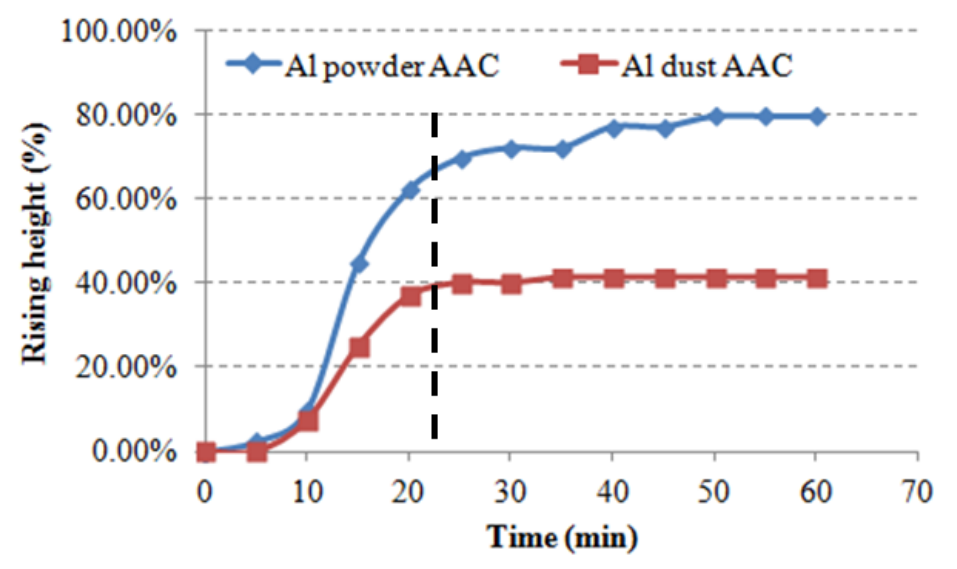

\section{Figure 9. Rising height development with time for Al powder AAC and Al dust AAC with 0.3\% metallic aluminum content}

Figure 10 shows the yield stress of $\mathrm{Al}$ powder $\mathrm{AAC}$ and $\mathrm{Al}$ dust dosage $\mathrm{AAC}$ with $0.3 \%$ metallic aluminum content. Generally, yield stress increases with time increases for both samples, and both samples achieved the same maximum yield stress. The yield stress curves can further be split into two stages. The first stage is before 23 mins. At this stage Al dust AAC has faster yield stress gain which results in higher yield stress than $\mathrm{Al}$ powder AAC. From the research paper [Melo et al 2014], higher yield stress results in smaller void size. So the rising height of Al dust AAC at first stage is lower than $\mathrm{Al}$ powder AAC. At the time of 23 mins, the corresponding yield stress is $230 \mathrm{~Pa}$ for $\mathrm{Al}$ dust AAC. This is the threshold yield stress for rising as after that Al dust AAC paste is not able to further rise shown in Figure 9. However, the yield stress for $\mathrm{Al}$ powder AAC is only $120 \mathrm{~Pa}$ at $23 \mathrm{mins}$, which is much lower than threshold value. So the Al powder AAC paste continues to rise until 38 mins, at which time the yield stress of $\mathrm{Al}$ powder AAC paste achieved the threshold value $230 \mathrm{~Pa}$. Therefore, the second stage is from 23 mins to 38 mins, during which $\mathrm{Al}$ dust $\mathrm{AAC}$ paste stop rising while $\mathrm{Al}$ powder AAC continues to rise. Take into consideration of stage one and two, totally $\mathrm{Al}$ dust $\mathrm{AAC}$ has lower rising height than $\mathrm{Al}$ powder $\mathrm{AAC}$, which results in the lower void ration of $\mathrm{Al}$ dust AAC. The higher yield stress gain in $\mathrm{Al}$ dust AAC is perhaps due to the high aluminum oxide content in $\mathrm{Al}$ dust, which absorbs much water when reacts with alkali as showed in the following equation:

$\mathrm{Al}_{2} \mathrm{O}_{3}+2 \mathrm{OH}^{-}+3 \mathrm{H}_{2} \mathrm{O} \rightarrow 2 \mathrm{Al}(\mathrm{OH})_{4}^{-}$

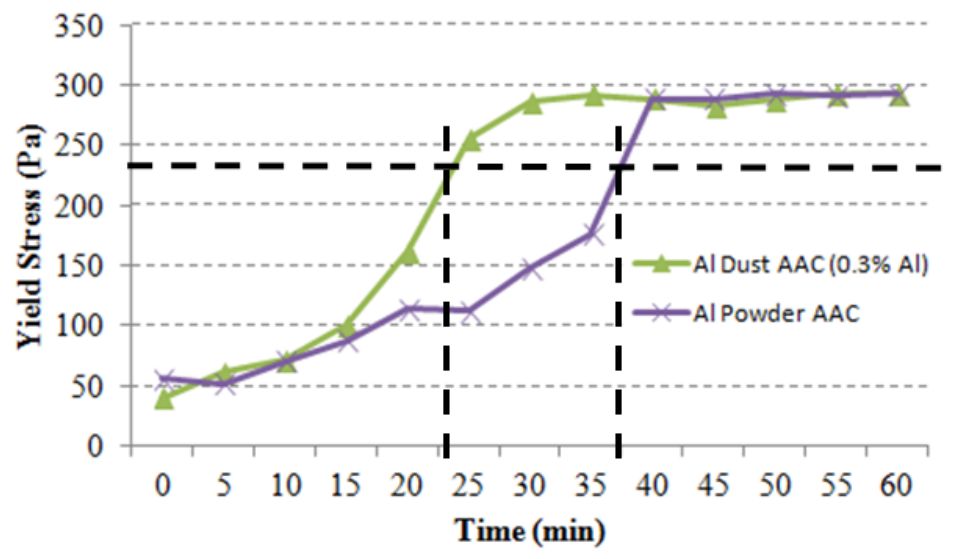

Figure 10. Yield stress of $\mathrm{Al}$ powder $\mathrm{AAC}$ and $\mathrm{Al}$ dust $\mathrm{AAC}$ with $0.3 \%$ metallic aluminum 
Figure 11 shows the void structure of cross section of Al dust AAC and Al powder AAC. As can be seen, the void size of $\mathrm{Al}$ dust $\mathrm{AAC}$ is smaller than $\mathrm{Al}$ powder $\mathrm{AAC}$, which verifies the above analysis.
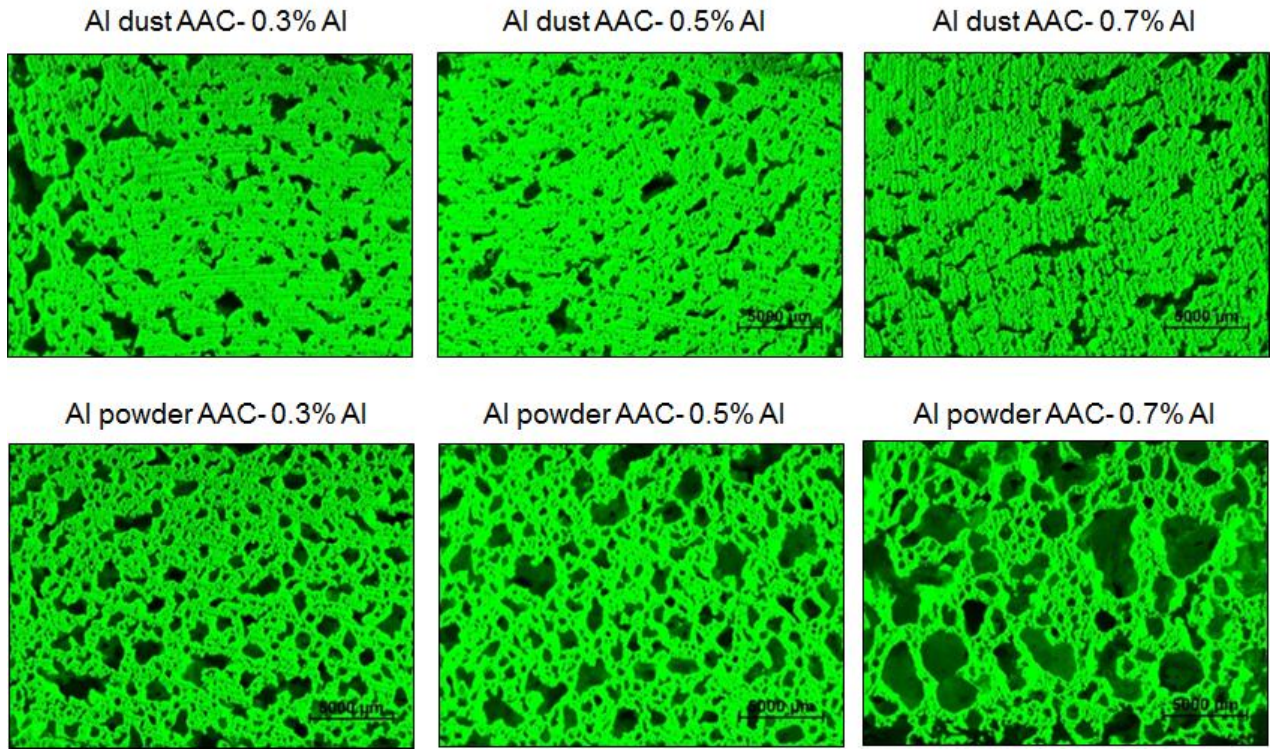

Al powder AAC- $0.7 \% \mathrm{Al}$

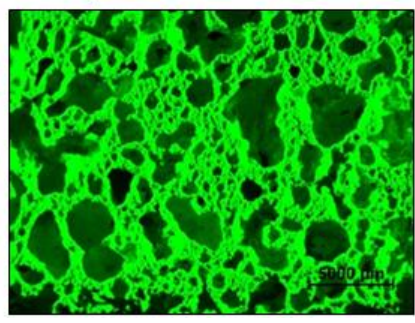

\section{Figure11. Void structure of Al powder AAC and Al dust AAC}

Figure 12 shows the change of rising height when metallic aluminum content increased from $0.5 \%$ to $0.7 \%$ for $\mathrm{Al}$ powder $\mathrm{AAC}$ and $\mathrm{Al}$ dust $\mathrm{AAC}$. Unlike $\mathrm{Al}$ powder $\mathrm{AAC}$, which has larger rising height increase, $\mathrm{Al}$ dust $\mathrm{AAC}$ has only a little bit rising height increase when metallic aluminum increases by $0.2 \%$, which results in little change of void ratio.

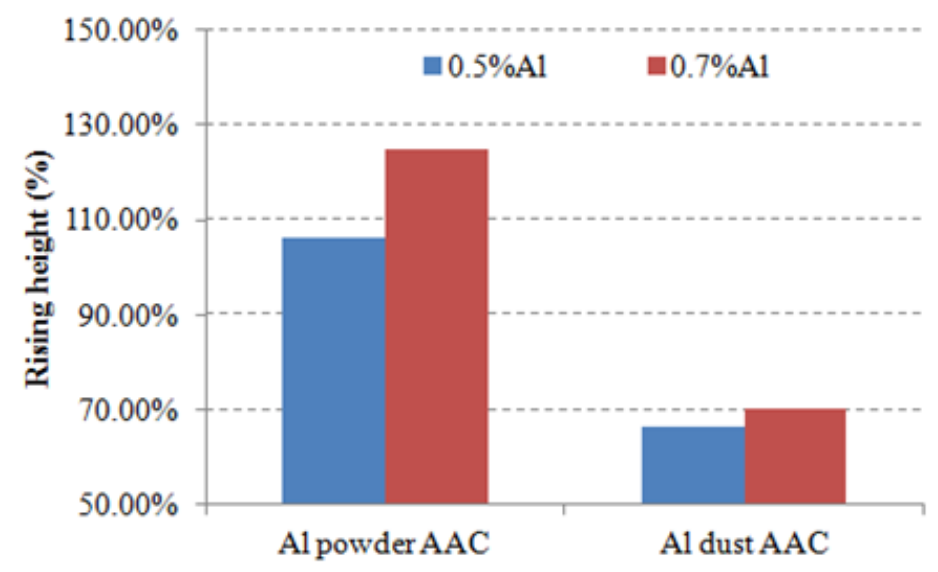

Figure 12. Rising height of $\mathrm{Al}$ powder $\mathrm{AAC}$ and $\mathrm{Al}$ dust $\mathrm{AAC}$ with metallic aluminum content $0.5 \%$ and $0.7 \%$

Figure 13 shows the yield stress of $\mathrm{Al}$ dust $\mathrm{AAC}$ with $0.5 \%$ and $0.7 \%$ metallic aluminum content. As can be seen, higher Al dust dosage leads to faster yield stress gain. Similar analysis can be done just like the analysis done for Figure 10, and it can be concluded that higher Al dust dosage lowers the rising height and void ratio, which sacrifices the gas generation capacity from more metallic aluminum content in $\mathrm{Al}$ dust with $0.7 \%$ metallic aluminum, and finally similar rising heights are gotten for both samples. 


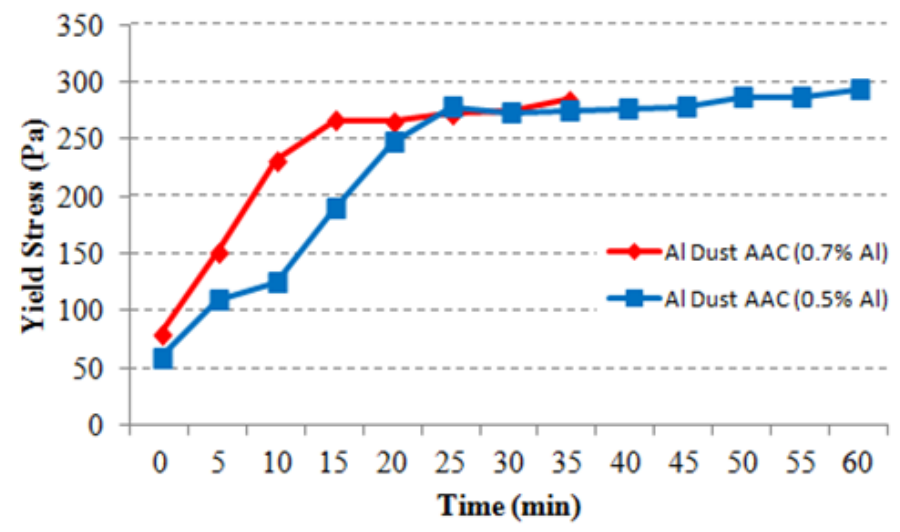

Figure 13. Yield stress of $\mathrm{Al}$ dust $\mathrm{AAC}$ with $0.5 \%$ and $0.7 \%$ metallic aluminum content

\section{CONCLUSION}

The following general conclusions can be drawn from the study provided in the paper:

- $\mathrm{Al}$ dust is able to be used as aerating agent to produce AAC. For gas generation capacity, $1 \mathrm{~g} \mathrm{Al}$ powder equals $15.6 \mathrm{~g} \mathrm{Al}$ dust.

- Al-dust AAC has smaller pore size, lower porosity, higher density and higher compressive strength than $\mathrm{Al}$ powder $\mathrm{AAC}$ due to faster yield stress gain.

- The void ratio of Al-dust AAC cannot be further increased by increasing Al dust dosage because higher Al dust dosage results in faster yield.

\section{ACKNOWLEDGEMENT}

The financial support from the Republic of Singapore's National Research Foundation through a grant to the Berkeley Education Alliance for Research in Singapore (BEARS) for the Singapore-Berkeley Building Efficiency and Sustainability in the Tropics (SinBerBEST) program is gratefully acknowledged.

\section{REFERENCES}

ASTM C 230 / C 230M. "Standard Specification for Flow Table for Use in Tests of Hydraulic Cement." 6 pages.

Ebadat, Vahid, and Richard W. Prugh. (2007). "Case study: Aluminum-dust explosion." Process Safety Progress, 26.4: 324-329.

Eckhoff, Rolf. (2003). "Dust explosions in the process industries: identification, assessment and control of dust hazards." Gulf professional publishing.

Melo, J. P., Aguilar, A. S., and Olivares, F. H. (2014). "Rheological properties of aerated cement pastes with fly ash, metakaolin and sepiolite additions." Construction and Building Materials, 65, 566-573.

Myers, Timothy J. (2008). "Reducing aluminum dust explosion hazards: Case study of dust inerting in an aluminum buffing operation." Journal of hazardous materials, 159.1: 72-80. 
Song, Yuanming, et al. (2015). "Feasibility study on utilization of municipal solid waste incineration bottom ash as aerating agent for the production of autoclaved aerated concrete." Cement and Concrete Composites, 56 (2015): 51-58.

Stephen T. Smith. (2003). "Disposal costs for treated wood as hazardous versus non-hazardous waste." <http://www.wwpinstitute.org/documents/DisposalCostsEvaluation2.pdf> (Jun. 29, 2015). 